\title{
Effect of conventional and sustained release sodium valproate on serum leptin and some liver function tests in epileptic patients
}

Sajid Kh Ameen*, Faris A Ahmed**

*Department of Pharmacology, College of Medicine, **Department of Physiology, Ninevah College of Medicine, University of Mosul, Correspondence: faris_mawjood@yahoo.com

$\frac{\text { Received }}{4.11 .2013} \quad \frac{\text { Accepted }}{15.12 .2013}$

\begin{abstract}
Objectives: To compare the effect between conventional and sustained released sodium valproate monotherapy on serum leptin, body mass index (BMI) and some liver function tests including serum alkaline phosphatase (ALP), alanine amino transferase (ALT), aspartate amino transferase (AST), albumin, total bilirubin (TB) and direct bilirubin (DB) in epileptic patients.

Patients and methods: The study is a case control study. It included 40 epileptic patients on conventional sodium valproate at doses $400-800 \mathrm{mg}$ per day, and 42 patients on sustained released sodium valproate at doses 500-1000 mg per day. Forty healthy subjects sex and age matched served as controls were also included in the study. Blood samples were taken from the patients and controls and analyzed for serum ALT, ALP, AST, albumin, total bilirubin and direct bilirubin. Serum leptin was also analyzed by using ElISA technique.
\end{abstract}

Results: Serum leptin, ALT, ALP, AST and TB in epileptic patients treated by conventional sodium valproate were significantly $(p<0.05)$ higher than that in patients treated with sustained release sodium valproate. However, serum albumin was significantly $(p<0.05)$ lower than that in patients treated by sustained released sodium valproate. No significant change was noticed between the two patients groups for BMI and serum DB

Conclusion: Sustained release sodium valproate may have less hepatotoxic effect and cause less weight gain than conventional sodium valproate. The reduced frequency of doses and the possibility of dosing flexibility may all improve compliance of the patients.

Keywords: Sodium Valproate, Liver function, epileptics.

هدف البحث: مقارنة بين تأثير عقار فالبروات الصوديوم التقليدي وطويل المفعول على مصل اللبتين ومؤشر كتلة

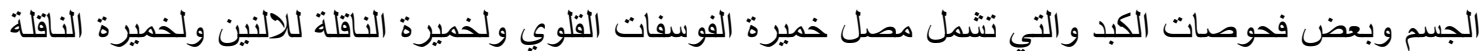

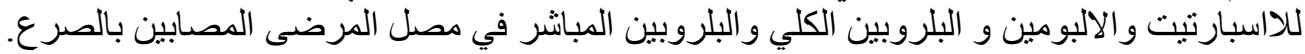

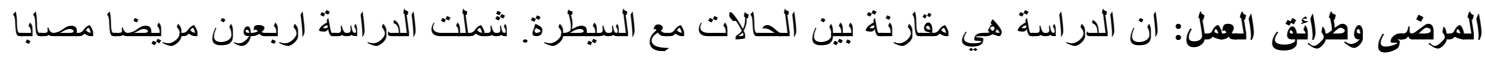

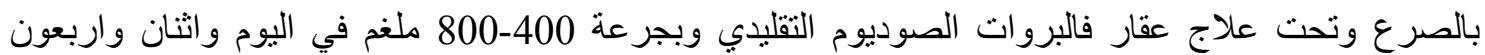

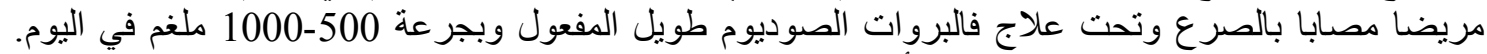

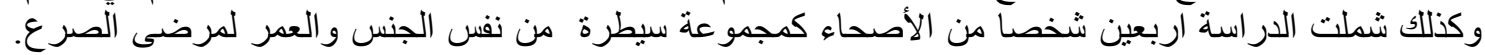

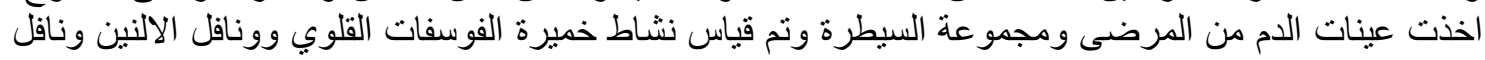

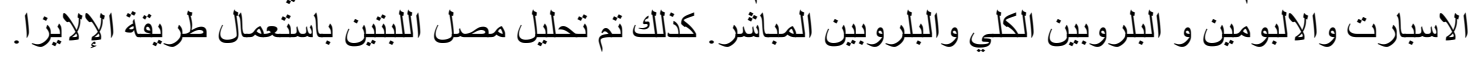

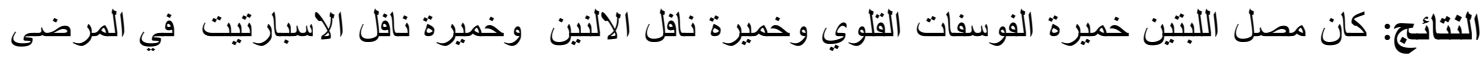

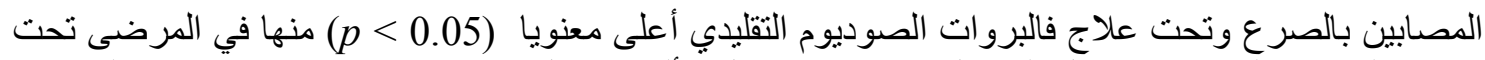

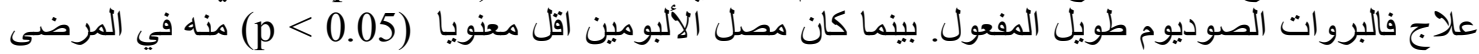




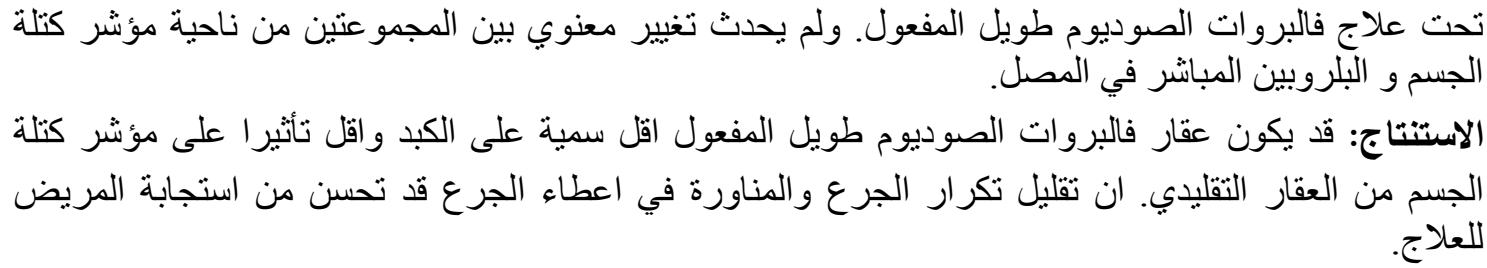

$\mathrm{S}$ odium valproate is the most effective antiepileptic drug in the treatment of idiopathic generalized epilepsy ${ }^{1}$. It also possesses efficacy in the treatment of various epileptic seizures such as absence, myoclonic, and generalized tonic-clonic seizures ${ }^{2}$.

Sustained (extended)-release formulations of valproic acid can be very helpful in achieving treatment objectives especially when switching from conventional to extended-release formulations of these agents ${ }^{3}$. Stable serum levels without marked peak-totrough fluctuations, reduced frequency of dosing, and the possibility of dosing flexibility may all improve compliance, seizure control ${ }^{4}$ or tolerability, particularly for tremor ${ }^{4,5}$, patient satisfaction and ultimately quality of life ${ }^{6,7}$.

Serum leptin and insulin levels were significantly elevated by sodium valproate in treated patients compared with untreated patients and with those received carbamazepin and lamotrigen therapy, suggesting that hyperleptinemia and hyperinsulinemia are common with sodium valproate among epileptic patients who gained weight as a sign of leptin and insulin resistance $^{8,9}$. However, sodium valproate did not cause a significant change in serum liptin in epileptic children ${ }^{10}$.

Several studies of the side effect of conventional sodium valproate on liver function were conducted ${ }^{11,12}$. However, few studies were done on the effect of sustained release sodium valproate on liver function. Kondo et al. ${ }^{13}$ suggested that sustained release formulation of sodium valproate may be safer on liver than conventional form of sodium valproate.

Since the effect of sustained release on BMI and serum liptin was not studied yet. In addition, the effect of sustained released sodium valproate on liver functions still need more evaluation. Therefore, this work was conducted in order to evaluate the effect of sustained released sodium valproate on BMI, serum liptin and some liver function tests. These results were compared with patients treated with conventional sodium valproate and with a control group.

\section{Patients and methods}

This work was conducted in a Private Clinic of Neurology in Mosul, during the period from October 2012 to June 2013. The study was approved by ethical committee of Ninevah Directorate (Health Medical Research Ethical Committee). Diagnosis and treatment of the patients were under supervision of a neurologist. The biochemical analysis was conducted at the Department of Pharmacology, College of Medicine, University of Mosul, Mosul, Iraq.

Two patient groups were included in this study. The first group included 40 patients, with age range 17-39 years (mean \pm SD: $23.57 \pm 5.59$ years), with generalized tonic clonic epilepsy, on conventional sodium valproate (Depakine ${ }^{\circledR}$, Sanofi-Aventis, France), at doses between 400 and 800 mg once or twice daily for at least six months. The second group included 42 
patients with age range 17-38 years (mean \pm SD: $23.89 \pm 5.05$ ), with generalized tonic colonic epilepsy, on sustained released sodium valproate (Depakine chrono ${ }^{\circledR}$, Sanofi-Aventis, France), at doses between 500 and $1000 \mathrm{mg}$ once or twice daily for at least six months. Forty apparently healthy volunteers as a control group were judged free from disease or medicine, with age range 17-38 years (mean \pm SD: $23.71 \pm 5.41$ years), were also included in the study.

Five $\mathrm{ml}$ of venous blood samples were taken from patients and controls, at about 8.00 to 10.00 a.m., and after an overnight fasting. The serum was divided into 2 parts and kept at $-20^{\circ} \mathrm{C}$, the first aliquot was used for the measurement of serum leptin ${ }^{14}$ and the other aliquot was used for the measurement of alkaline phosphatase (ALP), alanine amino transpherase (ALT), aspartate amino transpherase (AST), albumin, total bilirubin (TB) and direct bilirubin and albumin ${ }^{15}$.

Body mass index (BMI) was measured using the following formula BMI $=$ weight $(\mathrm{kg}) /$ height $(\mathrm{m})^{2}{ }^{16}$.

Data are presented as mean \pm SD and were analyzed using Anova test and Duncanś test to compare among different groups. Unpaired t-test was used to compare between groups.
Correlation coefficient (r) was also used to determine the relationship between the parameters and age, dose and duration of therapy. Statistical Package for Social Sciences (SPSS) version 17 was used for analysis of the data $^{17}$.

\section{Results}

Conventional sodium valproate significantly increased $(\mathrm{p}<0.05)$ BMI, serum leptin, ALT, AST, ALP and TB compared with the controls. However, serum albumin and DB were not changed significantly compared with the controls (Table 1).

Sustained release sodium valproate also significantly increased $(\mathrm{p}<0.05)$ serum leptin, AST and TB. On the other hand, BMI, serum albumin, ALT, ALP and serum DB did not change significantly compared with the controls (Table 1).

Serum leptin, ALT, ALP, AST and TB in patients treated by conventional sodium valproate were significantly $(p<0.05)$ higher than that in patients treated with sustained release sodium valproate. However, serum albumin was significantly $(\mathrm{p}<0.05)$ lower than that in patients treated by sustained released sodium valproate. No significant change was noticed between the two groups for BMI and serum DB as shown in Table 1. 
Table 1. Effect of conventional and sustained released sodium valproate on different parameters

\begin{tabular}{|lc|c|c|c|}
\hline \multicolumn{2}{|c|}{ Parameters } & Control group & $\begin{array}{c}\text { Conventional } \\
\text { Sodium valproate } \\
\text { group } \\
\mathrm{N}=40\end{array}$ & $\begin{array}{c}\text { Sustained released } \\
\text { sodium valproate } \\
\text { group } \\
\mathrm{N}=42\end{array}$ \\
\hline BMI & $\left(\mathrm{kg} / \mathrm{m}^{2}\right)$ & $22.35 \pm 1.82$ & $23.76 \pm 2.78^{\mathrm{a}}$ & $22.74 \pm 2.22$ \\
\hline Leptin $(\mathrm{ng} / \mathrm{L})$ & $7.31 \pm 3.00$ & $12.18 \pm 5.87^{\mathrm{a}}$ & $9.8 \pm 25.22^{\mathrm{bc}}$ \\
\hline Albumin & $(\mathrm{g} / \mathrm{L})$ & $4.17 \pm 0.41$ & $4.02 \pm 0.56$ & $4.29 \pm 0.42^{\mathrm{c}}$ \\
\hline AST & $(\mathrm{U} / \mathrm{L})$ & $21.61 \pm 7.20$ & $38.87 \pm 7.18^{\mathrm{a}}$ & $25.30 \pm 6.68^{\mathrm{bc}}$ \\
\hline ALT & $(\mathrm{U} / \mathrm{L})$ & $19.30 \pm 6.12$ & $60.69 \pm 10.09^{\mathrm{a}}$ & $16.84 \pm 7.79^{\mathrm{c}}$ \\
\hline ALP & $(\mathrm{U} / \mathrm{L})$ & $67.71 \pm 17.64$ & $130.02 \pm 40.38^{\mathrm{a}}$ & $66.10 \pm 17.50^{\mathrm{c}}$ \\
\hline TB & $(\mathrm{mg} / \mathrm{dL})$ & $0.65 \pm 0.25$ & $1.25 \pm 0.27^{\mathrm{a}}$ & $0.85 \pm 0.21^{\mathrm{bc}}$ \\
\hline DB & $(\mathrm{mg} / \mathrm{dL})$ & $0.28 \pm 0.13$ & $0.30 \pm 0.07$ & $0.26 \pm 0.06$ \\
\hline $\mathrm{a}, \mathrm{b}$
\end{tabular}

${ }^{\mathrm{a}, \mathrm{b}} \mathrm{p}<0.05$ from the control group; ${ }^{\mathrm{c}} \mathrm{p}<0.05$ from the conventional group. BMI, body mass index; AST, alanine aminotransferase; AST, aspartate aminotransferase; ALP, alkaline phosphatase; TB, total bilirubin; DB, direct bilirubin

\section{Discussion}

The current study demonstrated significant increase in BMI in epileptic patients receiving conventional sodium valproate, but it was not confirmed with epileptic patients receiving sustained release sodium valproate. Other studies are in agreement with this study for the significant increase BMI by conventional sodium valproate in epileptic patients ${ }^{18,19}$. However, divalproex, the sustained released sodium valproate was associated with superior tolerability with less weight gain compared with conventional sodium valproate ${ }^{20}$.

The results of this study revealed that serum leptin was significantly higher compared with the control group in epileptic patients receiving conventional sodium valproate and to a lesser extent with sustained released sodium valproate. These results were consistent for conventional sodium valproate with other workers ${ }^{9,21,22}$.

The two common homeostatic hormones, insulin and leptin, have been expected to form a common link to weight gain in epileptic patients receiving conventional sodium valproate $^{23}$. In addition, appetite can be stimulated by increased GABA transmission within the hypothalamic axis of central nervous system by conventional sodium valproate ${ }^{24}$. Sodium valproate also caused direct secretion of leptin from adipocytes ${ }^{25}$.

Serum ALT and AST and ALP were increased significantly in the present epileptic patients treated with conventional but not sustained released sodium valproate. The result regarding conventional sodium valproate group was in agreement with other studies ${ }^{26-}$ 29. The observed increase in enzyme activity in epileptic patients treated with conventional sodium valproate may be as a result of liver injury which 
altered hepatocyte integrity caused by sodium valproate pharmacokinetic interactions. In addition, serum biochemical changes, which indicate predisposition to development of rickets or osteomalacia appear within 90 days of starting carbamazepine or valproic acid monotherapy ${ }^{30,31}$.

The results showed significant increase in TB with no significant change in $\mathrm{DB}$ for both conventional and sustained release sodium valproate. The significant increase in TB with no significant changes in DB may be due to a defect in conjugation of bilirubin with glucuronate caused by the damaged hepatocytes leading to the leakage of bilirubin into circulation $^{32}$.

The altered pharmacokinetics and metabolism of sodium valproate after replacement of conventional sodium valproate with the slow-release formulation in epileptic patients, suggested smaller diurnal fluctuations in valproate concentrations during treatment with slow-release formulation of valproate resulted in lowered concentrations of the most toxic metabolites which associated with hepatotoxicity ${ }^{13}$.

In conclusion, serum leptin and some liver function tests in patients treated with conventional sodium valproate were higher than in patients treated with sustained release sodium valproate. Sustained release sodium valproate can be more safe on liver functionss with less adverse effect on BMI than conventional sodium valproate.

\section{Acknowledgement}

This work was supported by Mosul College of Medicine, University of Mosul.

\section{Reference}

1. Nicolson A, Appleton RE, Chadwick DW, et al. The relationship between treatment with valproate, lamotrigine, and topiramate and the prognosis of the idiopathic generalised epilepsies. J Neurol Neurosurg Psychiatry 2004; 75:75-9.

2. Johannessen CU, Johannessen SI. Valproate: past, present, and future. CNS Drug Rev 2003; 9:199216.

3. Perucca E. Extended release formulation of antiepileptic drugs: rational and comparative value . Epilepsy Curr 2009;9:153-7.

4. Doughty J, Baker GA, Jacoby A, et al. Compliance and satisfaction with switching from an immediaterelease to sustained-release formulation of valproate in people with epilepsy. Epilepsy Behav 2003;4:710-16

5. Zielinski D, Smith MC. The use of extended release formulation of divalproex in patients with epilepsy. Epilepsia 2001;42(7):92.

6. Bialer M. Pharmacokinetic evaluation of sustained release formulations of antiepileptic drugs, clinical implications. Clin. Pharmacokinet 1992;22:11-21.

7. Pellock JM, Smith MC, Cloyd JC, et al. Extended-release formulations: Simplifying strategies in the management of antiepileptic drug therapy. Epilepsy Behav 2004; 5:301-7.

8. Hamed SA. Leptin and insulin homeostasis in epilepsy: relation to weight adverse conditions. Epilepsy Res 2007;75:1-9.

9. Verrotti A,Torre R, Trotta D, et al. Valproate-Induced Insulin Resistance and Obesity in Children. Horm Res 2009;71:125-31.

10. Pylvanen V, Knip M, Pakarinen A, et al. Serum insulin and leptin levels in valproate - associated obesity. Epilepsia 2002;43:514-7.

11. Gökçe S, Durmaz O, Celtik C, et al. Valproic acid-associated vanishing 
bile duct syndrome. J Child Neurol 2010;25(7):909-11.

12. Ghozzi H, Hakim A, Sahnoun $Z$, et al. Relationship between plasma concentrations of valproic acid and hepatotoxicity in patients receiving high doses. Rev Neurol (Paris) 2011;167(8-9):600-6.

13. Kondo T, Tokinaga N, Suzuki A, et al. Altered pharmacokinetics and metabolism of valproate after replacement of conventional valproate with the slow-release formulation in epileptic patients. BCPT 2002; 90:135-8.

14. Chow VTK, Phoon MC. Measurement of serum Leptin concentration in university undergraduate by competitive Elisa reveal correlation with body mass index and sex. Advan Physiol Edu 2003;27:70-7.

15. Moss D, Henderson A. Clinical enzymology In : Teitz Text Book of Clinical Chemistry. Burtis CA , Ashwood ER ( eds ). 3rd ed., Saunders , Philadelphia , Pa , USA: 1999: p 617-721.

16. Leermarkers EA, Blair SN. Exercise management of obesity. Med Clin North America 2000;84:419-25.

17. Jones J. Pharmaceutical statistics. $8^{\text {th }}$ edition Pharmaceutical press, London 2002.

18. Martin CK, Han H, Anton SD, etal. Effect of valproic acid on body weight, food intake, physical activity and hormones: results of a randomized controlled trial. $\mathrm{J}$ Psychopharma-col 2009;23(7):81425.

19. Othman AO, Thanon IA. Effect of sodium valproate on serum leptin, C-reacive protin, oxidative stress and lipid profile in male epileptic patients. M.Sc. Thesis in pharmacology, College of Medicine, University of Mosul 2010.
20. Smith MC, Centorrino F, Welge $\mathrm{JA}$, et al. Clinical comparison of extended-release divalproex versus delayed-release divalproex: pooled data analysis from nine trials. Epilepsy behave 2004;5:746-51.

21. Greco R, Latini G, Chiarelli F, et al. Leptin, ghrelin, and adiponectin in epileptic patients treated with valproic acid. Neurology 2005;65:1808-9.

22. Aydin K, Serdaroglu A, Okuyaz $\mathrm{C}$, et al. Serum insulin, leptin, and neuropeptide $Y$ levels in epileptic children treated with Sodium Valproate. J Child Neurol 2005;20:848-51.

23. Hamid SA, Fida NM, Hamed EA. States of serum leptin and insulin in children with epilepsy: risk predictors of weight gain. Eur J Paediatr Neurol 2009;13(3):261-8.

24. Van den Pol AN. Weighing the role of hypothalamic feeding neurotransmitters. Neuron 2003; 40:1059-61.

25. Lagace DC, Mcleod RS, Nachtigal MW. Valproic acid inhibits leptin secretion and reduces leptin messenger ribonucleic acid levels in adipocytes. Endocrinology 2004; 145(12):5493-503.

26. Cepelak I, Zanić-Grubisić T, Mandusić A, etal. Valproate and carbamazepine comedication changes hepatic enzyme activities in sera of epileptic children. Clin Chim Acta 1998; 276(2):121-7.

27. Sonmez FM, Demir E, Orem A, et al. Effect of antiepileptic drugs on plasma lipids, lipoprotein (a), and liver enzymes. J Child Neurol 2006;21(1):70-4.

28. Patil B, Binjawadgi A, Anandi B, et al. A case of valproate induced hepatitis in an elderly subject. JEMDS 2013;21(29):5492-5494.

29. Tolou-Ghamari Z, Zare M, Habibabadi J, et al. Antiepileptic Drugs: a consideration of clinical and 
biochemical outcome in patients with epilepsy. Int J Prev Med 2013;4(supp 2):S330-S7.

30. Krishnamoorthy G, Karande S, Ahire N, etal. Bone metabolism alteration on antiepileptic drug therapy. Indian J Pediatr 2009;76:377-83.

31. Krishnamoorthy G, Nair R, Sundar U, et al. Early predisposition to osteomalacia in Indian adults on phenytoin or valproate monotherapy and effective prophylaxis by simultaneous supplementation with calcium and 25-hydroxy vitamin D at recommended daily allowance dosage: A prospective study. Neurol India 2010;58:213-9.

32. Friedman LS, Martin P, Munoz SJ. Liver function tests and the objective evaluation of the patient with liver disease. a textbook of liver disease. WB Saunders Philadelphia, 1996; p791-833. 